\title{
Uma ponte entre duas margens ou a triste história política da travessia do rio Oiapoque ${ }^{1}$
}

\section{A bridge between two banks or the sad political history of crossing the river Oiapoque}

Denis Fleurdorge

Departamento de Sociologia. Pesquisador LERSEM/IRSA. Universidade Paul-Valéry Montpellier 3 <Denis.Fleurdorge@univ-montp3.fr>

TRADUZIDO POR: Clélia Pinto

\section{RESUMO}

Este artigo aborda um caso concreto entre o Brasil e a França, noticiado em jornais, que se apresenta como um exemplo de impasse numa relação de comunicação, política, diplomacia e interesse social.

\section{ABSTRACT}

This article addresses a concrete case between Brazil and France, reported in newspapers, which presents itself as an example of impasse in a relationship of communication, politics, diplomacy and social interest.

Para que as "coisas" aconteçam socialmente, é preciso a conjunção harmoniosa e, por vezes, imprevisível do imaginário e do simbólico. Nos confins do Brasil, no Estado do Amapá e num improvável território francês - a Guiana -, a ideia de uma ponte entre duas margens germinou nas cabeças dos homens de poder, ferrenhos de símbolos políticos. A linha diretriz desta ideia consistia em construir uma ponte sobre um rio para ligar o Brasil e a França, a América do Sul e a Europa, o Novo mundo e o Velho mundo moribundo². A política é sempre uma maneira de brincar com os limites: limites imaginários, limites simbólicos, limites reais. Mas também, como sublinha com grande precisão Pierre Legendre, "o imutável cenário que sustenta o poder" necessita "do teatro, dos ritos, das cerimônias de escritura para poder fazer existir um estado, lhe dar forma, elaborar uma ficção viva"(Legendre, 1999, p. 9). O real é a aplicação de

1 Conferência proferida durante o XIII Seminário Internacional da Comunicação, realizado de 17 a 19 de novembro de 2015, na Pontifícia Universidade Católica do Rio Grande do Sul (PUCRS), sob a organização do Programa de Pós-Graduação em Comunicação, coordenado pelo prof. Dr. Antonio Hohlfeldt, da Faculdade de Comunicação Social da PUCRS.

2 O custo desse projeto seria de mais de 50 milhões de reais (o equivalente a mais de 20 milhões de euros). Isto não dá conta das "tradicionais ultrapassadas" de orçamento e de todos os gastos periféricos : estradas, estruturas, infraestruturas administrativas etc. 
uma vontade política de edificar uma ponte estaiada de um comprimento de 378 metros entre a margem brasileira e a margem guianesa do rio Oiapoque, num lugar chamado Ponta Morna. A origem de tal projeto remonta a uma vaga decisão,anunciada conjuntamente pelos presidentes Jacques Chirac e Fernando Henrique Cardoso, em $1997^{3}$.

O tempo, tendo feito sua discreta obra, o projeto ressurgiu no momento dos acordos franco-brasileiros, assinados no 15 de julho de 2005, durante uma visita oficial do Presidente Luiz Inácio Lula da Silva na França. Mas é no 12 de fevereiro de 2008, no momento do Acordo bilateral entre a França e o Brasil em Saint-Georges-de-L'Oyapock,que o projeto será recolocado no centro das relações franco-brasileiras. A primeira imagem é aquela do Presidente Nicolas Sarkozy em paletó e gravata, sobre um pontão improvável, perdido em plena floresta equatorial. Enquadrado por dois Guardas republicanos em calça branca e com sabre desembainhado (uniforme e postura de aparato), e de dois marinheiros da Marinha Nacional. Imagem insólita que dá ênfase à chegada do Presidente Lula. Com efeito, o Presidente brasileiro atravessa o rio em uma embarcação superlotada de homens armados e acosta com sua bela equipagem no lado guianês. A impressão desta teatralização barroca produz uma espécie de "imagem escópica", simbolizando a história olhando para o presente e o presente olhando para a história, num transtorno do sentido da conquista: Conquistadores de uma outra épocas e inscrevendo no símbolo irrisório do tempo presente, e do elo não conflituoso entre Conquista e Liberdade, entre Novo mundo e Antigo mundo, entre Progresso e Sub-desenvolvimento.

\section{De uma margem a outra}

A Guiana, antiga colônia penitenciária, não produz nada no sentido produtivista contemporâneo, e oferece um turismo limitado, até embrionário. Ela só encontra uma justificativa honesta no desenvolvimento lucrativo da

3 No dia 11 de março de 1997, o presidente Jacques Chirac, na época de um tour diplomático pelos principais países da América do Sul, pronuncia um discurso em Brasília, no qual ele sugere a ideia de organizar uma cúpula entre os chefes de estado latino-americanos e europeus. No dia 28 e 29 de junho de 1999 acontece no Rio de Janeiro uma cúpula na qual participam 49 chefes de estados da América Latina, do Caribe, da União Europeia. Esta cúpula coloca no centro dos seus debates a questão do lugar, em termos de trocas e de cooperação, entre os dois continentes. Frente à dominação dos Estados Unidos, uma resposta conjunta deveria ser conduzida no âmbito político, econômico e cultural. Nós noteramos pela "pequena história" que, frente ao presidente Fernando Henrique Cardoso, Jacques Chirac ficou confuso, evocando, na continuação do projeto, esta magnifíca estrada que permitiria religar, antes de 2000, a Venezuela a Buenos Aires, velha lembrança, sem dúvidas, de cunho geográfico da mítica "panamericana" que ia do Alasca à Patagônia. 
indústria aeroespacial com a base de Kourou ${ }^{4}$ e como terreno de "jogo" da Legião Estrangeira ${ }^{5}$ para o seu treinamento em meio hostil. É um pedaço da França no meio do nada. Esta terra exuberante, mas pobre, permitiu "deportar" em toda humanidade os $\mathrm{Hmong}^{6}$ fugitivos do Laos nos boat people. Perfeitamente inseridos na nova terra prometida e na liberdade reencontrada, se tornaram jardineiros ${ }^{7}$. Talvez dentro do espírito de alguns atores políticos, a Guiana possa se tornar uma passagem para as exportações da Europa no continente sul americano. Mais uma vez uma "profecia autorrealizadora",uma desmesurada utopia social. Incapaz de controlar suas fronteiras, que seja com o Suriname ou com o Brasil, a fronteira administrativa francesa não existe frente às incessantes trocas fronteiriças.

Os homens, os animais (raros e protegidos) e as mercadorias (mais ou menos lícitas) circulam em um vai e vem secretamente codificado. A miséria e a pobreza levam, frequentemente, os mais precários a se perderem em trajetórias de vida mortais. Atração pelo que brilha, atração pelo dinheiro fácil e as sensações da vida clandestina.

Frente à Saint-Georges-de-l'Oyapock, na margem direita, se situa a pequena cidade de Oiapoque,cidade isolada ao norte do Estado do Amapá. É bem uma terra do fim do mundo, distante em mais de 600 quilômetros de Macapá. Ironia do destino ou da realidade, o Estado do Amapá não possui alguma ponte que o ligue ao resto do Brasil! Como na Guiana, aqui também a precariedade econômica da existência necessita de se arranjar com a fronteira.

Este arranjo é feito de território de conquista, de correrias febris, de acomodações com as leis instauradas. A pequena cidade de Oiapoque concentra tudo que o imaginário do enriquecimento rápido pode trazer, como força de atração e de resignação na desilusão.

Ela constitui um triste lugar de fixação humana, permitindo a alguns brasileiros, em frequente situação de extrema vulnerabilidade, de atravessar o rio e de encontrar não apenas um trabalho não declarado, mas também uma possível escolarização para seus filhos e um atendimento médico. Ela permite ao garimpeiro negociar o fruto de seus tráficos porque, mesmo se nenhuma das explorações de ouro não é recenseada no Estado do Amapá, existem vários balcões de venda que podem recuperar este ouro ilegal, não para "limpar",

4 Esta zona geográfica, pouco habitada, é interessante pois oferece uma trajetória equatorial ideal para o lançamento de foguetes.

5 Terceiro Regime Estrangeiro de Infantaria (3 ${ }^{\text {ème }}$ R.E.I., sigla no original) de Kourou ao Centro de Treinamento da Foresta Equatorial (CEFE, sigla no original) de Regina.

6 Os Hmong foram repartidos em quatro vilas: Cacao, Corossony, Javouhey e Roccocoua.

7 A comunidade Hmong investiu no desenvolvimento da cultura de lavouras e forneceu grande parte dos legumes da Guiana. 
mas para "redourar", num certo sentido". O garimpo clandestino fornece não apenas um comércio ligado à extração do ouro, mas também um mercado para a compra de bombas hidráulicas, geradores, ferramentas, armas e provisões.

Em linha direta desta economia das "margens", convém acrescentar o comércio proibido de animais exóticos e sob proteção - esta última atividade sendo específica das duas margens do Oiapoque. In fine, existe bem uma economia paralela que permite a gravitação de todo um universo de "pequenas profissões", constituindo uma mão de obra de serviços, tais como os garimpeiros ilegais, contrabandistas e prostitutas. O que singularmente caracteriza essas "experiências de vida" é uma fluidez nas relações que se tornaram invisíveis pela livre circulação de um comércio às fronteiras do lícito e do ilícito. $O$ "povo das margens" é composto, literalmente, "de seres fronteiriços que não têm fronteiras"(Simmel, 1988).

Desta forma, segundo um tipo de "transmutação simbólica", deve não apenas ligar,mas também inventar a fronteira, como a exprime justamente Régis Debray (2010, p. 16):"Relevos e cursos de água têm um poder incitativo de sugestão, mas não podem alcançara dignidade de fronteiras, que por um ato de inscrição solene, capaz de transmutar um acidente da natureza em uma regra de direito. [...]". Compreendemos bem que "a fronteira é em primeiro lugar uma questão intelectual e moral". Mais ainda, e isso é a proposta central deste artigo, se coloca a questão de um reconhecimento instituído sob forma cerimonial de inauguração da ponte pelas autoridades francesas e brasileiras. A natureza do rio e a cultura - a de uma visão administrativa - se concentram em uma imperativa necessidade de se juntar numa visão política única, e alimentam esta ilusão de "um ato de inscrição solene" e de transmutação em "uma regra de direito". Atingimos mais ainda esta vontade sempre renovada do político de provocar, como sublinha Pierre Legendre (1999, p. 47), "a indelével nostalgia dos lugares e dos emblemas, mas também a imobilidade do tempo que leva a acreditar na imortalidade, é o sinal, sempre vivo, do que o Ocidente chama de Nação".

\section{O real político não existe}

O olhar sociológico, que passa através das trocas humanas e da labilidade das relações sociais, permite antes de tudo colocar em relevo a expressão de uma experiência humana particular. Os ameríndios das duas margens não são nem brasileiros, nem franceses: eles são homens da floresta e do rio. Na verdade, os autóctones não têm nenhum interesse por esta ponte. Mais ainda, o símbolo político não lhes diz nada e sua utilidade funcional não tem nenhuma justificativa.

8 No Brasil, é o Estado que tem o monopólio de extração e da comercialização do ouro. 
A este nível da análise se situam a intimidade da produção dos símbolos políticos e sua eficácia. Com efeito, a "germinação simbólica" não se sustenta mesmo se, como sugere Georg Simmel (1988, p. 159), "é preciso primeiro que as coisas estejam distantes umas das outras para em seguida estarem umas com as outras. Seria absurdo, praticamente e logicamente, de ligar o que não estava separado, até o que nunca fica separado num certo sentido". Esta ponte, louvável ambição entre dois países mais que amigos, não existe simbolicamente. As duas margens estão separadas politicamente como uma descontinuidade territorial: uma margem brasileira e uma margem francesa. É, também, a conjunção dos imprevistos da história e de uma concepção administrativa e soberana do território. Mas para que estas duas margens sejam ligadas, foi preciso a lenta maturação de um sentido:

A ponte simboliza a extensão da nossa esferavolitiva no espaço.Para
nós e apenas para nós, as margens do rio não são simplesmente
exteriores uma a outra, mas justamente 'separadas'; e a noção de
separação seria desprovida de senso se não houvéssemos começado
a Ihes associar, em nossos pensamentos finalizados, nas nossas
necessidades, na nossa imaginação. Mas a partir deste momento, a
forma natural vem se ligar com esta noção, através de uma intenção
positiva, e a separação parece então intervir entre os elementos
adquiridos em si e para si, afim de que o espírito, conciliante,
unificante, a ultrapasse doravante (Simmel, 1988, p. 160-161).

Simmel aponta esta necessidade imperiosa de que o separado deve ser concebido inicialmente como separado, para, em seguida, ser ultrapassado: "Porque o homem é um ser de ligações que deve sempre separar, e que não pode se ligar sem ter separado - precisamos primeiro conceber em espírito como uma separação a existência indiferente de duas margens, para poder ligálas com uma ponte. E o homem é igualmente um ser-fronteira que não tem fronteira" (Simmel, 1988, p. 166).

O problema de fundo é que jamais este território esteve separado sociologicamente e antropologicamente. Então, para sair desta "instabilidade simbólica", deste impasse, é preciso considerar a situação como uma experiência humana de uma "última fronteira". Neste sentido, Régis Debray é de grande exatidão:

A fronteira sobrevive a suas metáforas. Invencível porque boa para pensar, pelo fato que toda organização simbólica de um caos ou de uma miscelânea passa, a cada vez, por um jogo de oposições - yin/ yang, feminino/masculino, quente/frio, terra/céu, como também clássico/barroco, apolíneo/dionisíaco, esquerda/direita etc. É a razão 
pela qual, se nem sempre existe fronteira, sempre existe uma última fronteira (Debray, 2010, p. 45-46).

Assim, de maneira simétrica, essa ponte sobre o rio Oiapoque oferece também seus jogos de oposição entre lícito/ilícito, riqueza/miséria, Ameríndio/ Europeu, Velho mundo/Novo mundo, conquista/abandono, economia/social.

Essa"ideia" de ponte se encontra como uma saída do caos de uma natureza indomável e de uma economia escura (tráfico, clandestinidade, ilegalidade) e cravada num mundo paradoxal que quer se libertar de todas as fronteiras: uma Europa sem fronteiras em um mundo globalizado. É importante sublinhar que esta fronteira internacional, delimitando o território do Brasil e o território da França, representa para a França sua mais longa fronteira territorial com um único país, com mais de 730 quilômetros.

\section{Da estranheza à figura do estrangeiro}

Desde Platão, sabemos que não existe identidade sem alteridade ou de alteridade sem identidade. Em outras palavras, a identidade como a alteridade vêm da mesma água. Das profundezas batismais do reconhecimento social, o Outro (alteridade) e o Mesmo (identidade) se confundem numa dialética entre relacionamento e duelo. Elos mantidos entre filiações e conflito de interpretações. Para além de uma aparente contradição, estes conceitos não podem existir um sem o outro. Identidade e alteridade, irmãs siamesas, devem se pensar e se praticar em todas as formas de relações sociais. A vida social participa conjuntamente do Mesmo e do Outro. Nascem e morrem num mesmo movimento. Em sua breve digressão sobre o "estrangeiro", Georg Simmel (1999) estabeleceu a importância das construções sociais dos espaços nas interações. Lá onde a indeterminação e as zonas escuras do social oferecem uma sociabilidade particular que permitiria o encontro com "a estranheza", vai se substituir a figura contemporânea do "fronteiriço estrangeiro brasileiro" (figura administrativa e forçosamente suspeita). Em retorno, o guianês das margens se tornara também um "fronteiriço estrangeiro guianês" (outra figura também suspeita). Eles devem, tanto um como outro, se desfazer da sua "estranheza" construída na experiência de uma alteridade do cotidiano e de uma sociabilidade adaptativa, para se tornar estrangeiros, devendo se incarnar numa identidade reificada: figura de direito potencialmente aberta às intrigas da administração policial e aduaneira.

In fine, a ponte supunha instaurar uma respiração social, até uma transpiração sob os rigores do clima equatorial. A fronteira aparece, então, como um envelope protetor simbólico, uma pele que, além da metáfora, pode ser um prolongamento metonímico: "A pele seria o órgão primordial das epigêneses, $\mathrm{O}$ 
primeiro reconhecível no embrião. É em se dotando de uma camada isolante, cujo papel, portanto, não consiste em proibir, mais sim em regular a troca entre o fora e o dentro que um ser vivo pode se transformar e crescer" (Debray, 2010, p. 37). Trata-se de uma regulação de formas e de trocas entre o "dentro" e o "fora". Verdadeira osmose das trocas sociais.

\section{A dura abertura simbólica do político}

O que seria da França sem sua administração? Ela foi a ponta de lança do projeto, o que a conduziu a terminar a construção depois de quatorze anos de obras (entre 1997 e 2011). Consciente da funcionalidade de uma fronteira, velha experiência histórica, com base nas longas tradições de guerras de fronteiras, a França oferece as infraestruturas administrativas à altura do projeto: Aduanas, direitos indiretos e serviço da Polícias das Fronteiras. Assim, os efetivos da polícia aumentaram, uma vez que 62 policiais estão atualmente responsáveis por este pedaço da fronteira9. Menos confessável e mais discretamente aplicado é o aumento das atividades militares, com uma verdadeira militarização da região, em torno das operações contra os garimpeiros brasileiros "prospectando" no território guianês ${ }^{10}$. Dito de outra maneira, a vigilância e o controle dispõem de meios, permitindo resolver o risco inerente a uma fronteira, já que "ela inibe a violência e pode justificá-la. Sela uma paz, desencadeia uma guerra. Reprime e libera. Dissocia e reúne. Como o rio, que aproxima e separa ao mesmo tempo" (Debray, 2010, p. 30). Isto explica, em parte, que para a França "A passagem lícita" é liquidada em proveito da "passagem punida" (Debray, 2010, p. 54). Assim, do lado francês o punir está pronto, estabelecendo uma zona de controle com aduana, visto e administração, mais ou menos minuciosa. Inevitavelmente, a ponte vai destruir a frágil economia feita por uma parte de zona social escura sob a luxuriante canopeia. E como sublinha Pierre Legendre (1999, p. 15): "A administração não existiria sem seu exagero teatral, sem seu cenário, sem sua potência formalista".

Os brasileiros falam de faroeste. Terra de conquistas e de liberdades, de todos os possíveis impossíveis, mas também de todos os tráficos e excessos. Não escapamos à sombra projetada da Grande floresta com o imaginário improvável e turvo de um faroeste à brasileira. Na margem brasileira,as obras ficaram atrasadas. As infraestruturas fronteiriças se reduzem a um simples

9 Este novo desenvolvimento administrativo permitiu a "recondução" à fronteira de 2000 brasileiros ilegais. Complicando a situação, os franceses que vinham da Guiana não precisavam de visto, ao passo que os brasileiros foram submetidos a uma obrigação de demanda e obtenção do visto para ir à Guiana. 10 Em junho de 2012, a realidade foi de uma extrema brutalidade uma vez que dois militares (um chefe e um ajudante) do $9^{\circ}$ Regime de Infantaria da Marinha "caíram" em combate e dois policiais foram machucados durante uma operação "Harpie" contra mineiros clandestinos. 
barraco. O Governador do Amapá, Camilo Capiberibe (PSB), decide relançar a continuação das obras do lado brasileiro, em agosto de 2011. É verdade que, deste lado do rio, tudo está ainda a ser feito. A BR 156, que leva à cidade de Macapá, precisa ainda ser estabilizada e asfaltada ao longo de 200 quilômetros. A isto se soma uma trintena de obras de arte (pontes por essencial!). Tudo isso é só o lado visível da realidade do empreendimento, uma vez que se adiciona, a um tal projeto, todas as negociações bilaterais entre a França e o Brasil, não apenas sobre as questões dos acordos além-fronteiras, de modificação dos direitos (vistos), mas também dos ajustamentos econômicos, sabendo-se que o Amapá é um Estado pobre, distante do desenvolvimento atual do Brasil. Em tal contexto, quais desenvolvimentos econômico, cultural, político e social são viáveis entre os dois países?

Essa "ponte emblema" traduz uma difícil abertura do político: nada germinara da realização deste projeto. Os símbolos políticos importados não têm nenhuma utilidade para os povos do rio e da floresta, que correm o risco de verem ameaçado o equilíbrio precário de suas vidas, cujas sociabilidades também recompostas oferecem uma espécie de lubrificante essencial às engrenagens de uma máquina social colocada em equilíbrio entre as duas margens de um rio perdido em plena floresta equatorial. Fica claro que existe uma tentativa "forçada" de manter um elo social entre a França e o Brasil, entre o Velho mundo e o Novo mundo, entre a Europa e um país de crescimento miraculoso que faz parte dos BRIC. Trata-se, também, como pano de fundo, do aumento dos vestígios de uma dominação cultural ou ainda de certa condescendência social? Sentimos a condescendência do Velho mundo a respeito do Novo mundo. Velho mundo que sempre ajustou a visão do mundo à sua imagem. Mas entre o saber e o desconhecimento desta condescendência política se cristaliza uma "visão terceiro-mundista" de "país emergente", enquanto que o Brasil é um pais soberano, moderno e industrial, inovador em vários domínios ${ }^{11}$.

Essa ponte é o signo diacrítico - literalmente que "distingue"- e o emblema realizado do que permite impor nossa "visão do mundo", um mundo mitológico, constituído por uma crença na capacidade do político em provocar a mudança social e instituir o desenvolvimento. O paradoxo é tergerado uma fronteira aonde não existia (ou talvez apenas uma fronteira imaginária) e uma ponte inutilizável, para criar uma pseudo-fronteira real. Antes da ponte, o encontro

11 O que a Europa não enxerga sobre o Brasil é que em uma grande parte, econômica, prevalece uma visão voltada para o modelo norte-americano de desenvolvimento. A velha Europa mantém a imagem distante e a nostalgia de uma velha cultura das humanidades emancipatórias, mas certamente não de um ideal de sociedade moderna. O Brasil não está mais em emergência, ele está na realização de um desenvolvimento de recuperação e de padronização do modelo norte-americano. 
entre franceses e brasileiros era possível, por razões amigáveis ou de troca de uma mesma "sociabilidade fluvial", para paliar a rudez das relações sociais e econômicas ${ }^{12}$. Assim, o que dizer desta ponte cuja estrada não foi inteiramente asfaltada e que leva a uma cidade sem ligação com o resto do Brasil (delta do Amazonas)? Quais serão as consequências para os habitantes, uma vez que as trocas econômicas são inexistentes e se situam em um impasse formal em termos de desenvolvimento? Defato, a ponte não altera em nada a realidade das práticas habituais. Ponte no meio do nada como um símbolo derrisório ${ }^{13}$, de um capricho e de um fantasma político repousando sobre um poder sem limites para a construção do futuro. Mas tudo isso é também sintomático da história da França, como uma sedimentação longa, lenta e improvável entre colbertismo e jacobismo, na medida em que essa "ideia maravilhosa" é francesa.

\section{Para concluir}

Por vezes, a realidade parece encontrar a ficção. Assim, a ficção cinematográfica nos oferece a alegoria do que pode ser uma vontade desmesurada, cristalizada num projeto insensato. Em 1982, no filme Fitz carraldo, Werner Herzog ${ }^{14}$, inspirando-se numa história verdadeira, apresentam painel barroco de um projeto tão audacioso quanto real: construir um teatro em lquitos no meio da floresta amazônica - lado peruano - para que o grande Enrico Caruso e a divina Sarah Bernhardt pudessem interpretar Verdi. O resultado foi outro e fez o europeu se confrontar com os vestígios das suas ilusões eo Ameríndio, em plena aculturação,com uma modernidade que pensa e se realiza sem ele. Introduzir a cultura nesta natureza luxuriante é uma bela metáfora para a decadência do Velho mundo como Novo mundo confrontando-se aos horrores de sua história presente e tumultuosa.

Quem quer ligar as duas margens? Uma vontade política, mas não certamente os ribeirinhos. Existe aí uma oposição entre a ideia da passagem e a ideia da continuidade territorial sem obstáculos. Visão e concepção política à parte de toda construção local e social, superposição da visão de um mundo

12 Nós assistimos à destruição programada das relações sociais frágeis que levaram, ao longo dos anos, ao desenvolvimento de amizades sólidas, dos casamentos e das cooperações tácitas. Na prática, os brasileiros não vão poder mais ir à Guiana.

13 Na França, nós já temos a experiência da ponte Saint-Bénézet que nunca foi finalizada e que não serve a ninguém. Mas graças ao espírito francês esta "prática inutilizada" foi rentabilizada pela influência das visitas turísticas pagantes. Esta ponte, em posição fronteiriça entre o Estado pontifício e o território da França, deveria ser um dos únicos para atravessar a região de Rhône pelos quilômetros rio acima e abaixo. Além disso, é um bom modo de coletar taxas sob as formas de pedágio ou de caridade a Saint-Bénézet. Esta ponte é mais conhecida pelo nome de ponte de Avignon. Talvez seja uma ideia a se considerar.

14 Filme alemão de Werner Herzog, Fitzcarraldo, 1982. 
descontínuo e territorializado e de um mundo contínuo e livre onde a natureza é mais forte que a cultura. Pois frente a uma entropia social, real ou figurada, é necessário discernimento e referencial num contexto de: "limite móvel e fluido, que vai e vem com as estações, as relações de força entre espécies e populações" (Debray, 2010, p. 16-17). Ainda mais: "Nós precisamos do instituído: nós plantamos signos, construímos emblemas" (Debray, 2010, p. 16-17).

Ao fundo da reflexão, todo território, concebido como tal, é uma sábia construção política ideal e idealizada. O território não é vivo simplesmente por estar investido de vidas humanas, mas também porque é o lugar privilegiado de uma articulação possível dos jogos de poder e de sua legitimidade. Pierre Legendre lembra com justeza que:

O território é uma construção política, pois é em primeiro, como se dizia da arte na renascença, o retrato da terra, uma imagem monumental, onde o homem procura encontrar o que existe de mais humano, uma semelhança com ele mesmo. É por isso que o território é um material vivo para as Administrações, o espaço onde se revela a relação de poder, uma relação que toca à identidade, melhor dizendo, o amor da nossa própria imagem. O território é uma humanidade colocada em forma, que faz corpo com os lugares, Ihes decifrando e habitando (Legendre, 1999, p. 31).

Essa ponte que poderia ser uma ponte entre duas margens, será apenas uma ponte para duas margens, por indiferença e falta de cultura política entre o para como injunção e confinamento, e o entre como composição e reificação possível.

A Presidenta do Brasil, Dilma Rousseff, e o Presidente francês, François Hollande, deviam inaugurar a ponte em dezembro de 2013, e desde então o black-out é completo do lado político. Felizmente que, frente a "uma certa imagem da França"15 temos a figura tranquilizadora, quase ideal-típica, do "homem cordial".

15 Isto é uma alusão à célebre frase de Charles de Gaulle "Por toda a minha vida, eu criei uma certa imagem da França. O sentimento me inspirou tanto quanto a razão. O que existe, em mim, de afetivo, imagina naturalmente a França tal qual a princesa de contos ou a madona dos afescos de paredes, como condenda a um destino eminente e excepcional" Mémoires de guerre - L'Appel 1940-1942, Tome 1 (Paris, Plon, 1954), p.1. 
Referências:

DEBRAY, Régis. Eloge des frontières. Paris: Gallimard, 2010.

LEGENDRE, Pierre. Miroir d'une Nation. L'Ecole d'Administration. Paris: Mille et Une Nuits, 1999.

SIMMEL, Georg. "Pont et porte”, dans La tragédie de la culture et autres essais. Paris: Editions Rivages, 1988.

La tragédie de la culture et autres essais. Paris: Editions Rivages, 1988.

. Etudes sur les formes de la socialisation. Sociologie, p. 663-684, Paris: PUF, 1999.

Recebido em: 9/5/2017

Aceito em: 9/5/2017

Endereço do autor:

Denis Fleurdorge <Denis.Fleurdorge@univ-montp3.fr>
Departamento de Sociologia
Universidade Paul-Valéry Montpellier 3
34 Route de Mende
34090 Montpellier - França

